\title{
On the Use of an Innovative Trend Analysis Methodology for Temporal Trend Identification in Extreme Rainfall Indices Over the Central Highlands, Vietnam
}

\section{Dang Nguyen Dong Phuong}

Nong Lam University Ho Chi Minh City

Nguyen Thi Huyen

Nong Lam University Ho Chi Minh City

Nguyen Duy Liem

Nong Lam University Ho Chi Minh City

Nguyen Thi Hong

VNU University of Science, Vietnam National University

Dang Kien Cuong

Nong Lam University Ho Chi Minh City

Nguyen Kim Loi ( $\square$ ngkloi@hcmuaf.edu.vn )

Nong Lam University Ho Chi Minh City https://orcid.org/0000-0002-3063-6910

\section{Research Article}

Keywords: Central Highlands of Vietnam, ETCCDI indices, Innovative trend analysis, Partial trend, Rainfall extremes.

Posted Date: August 10th, 2021

DOl: https://doi.org/10.21203/rs.3.rs-773078/v1

License: (c) (i) This work is licensed under a Creative Commons Attribution 4.0 International License. Read Full License

Version of Record: A version of this preprint was published at Theoretical and Applied Climatology on November 20th, 2021. See the published version at https://doi.org/10.1007/s00704-021-03842-3. 


\title{
ON THE USE OF AN INNOVATIVE TREND ANALYSIS METHODOLOGY FOR TEMPORAL TREND IDENTIFICATION IN EXTREME RAINFALL INDICES OVER THE CENTRAL HIGHLANDS, VIETNAM
}

\author{
Dang Nguyen Dong Phuong \\ Research Center for Climate Change, Nong Lam University Ho Chi Minh City, Ho Chi Minh City, Vietnam \\ Email: dangnguyendongphuong@gmail.com \\ ORCID iD: https://orcid.org/0000-0001-8881-5105 \\ Nguyen Thi Huyen
}

Faculty of Environment and Natural Resources, Nong Lam University Ho Chi Minh City, Ho Chi Minh City, Vietnam Email: nt.huyen@hcmuaf.edu.vn

\section{Nguyen Duy Liem}

Faculty of Environment and Natural Resources, Nong Lam University Ho Chi Minh City, Ho Chi Minh City, Vietnam Email: nguyenduyliem@hcmuaf.edu.vn ORCID iD: https://orcid.org/0000-0001-5151-4560

\section{Nguyen Thi Hong}

Faculty of Geology, VNU University of Science, Vietnam National University, Hanoi, Vietnam

Email: nthong@vnu.edu.vn

\section{Dang Kien Cuong}

Faculty of Information Technology, Nong Lam University Ho Chi Minh City, Ho Chi Minh City, Vietnam

Email: dkcuong@hcmuaf.edu.vn

Nguyen Kim Loi (Corresponding Author)

Research Center for Climate Change, Nong Lam University Ho Chi Minh City, Ho Chi Minh City, Vietnam

Email:ngkloi@hcmuaf.edu.vn

ORCID iD: https://orcid.org/0000-0002-3063-6910

\begin{abstract}
Understanding past changes in the characteristics of climate extremes (such as frequency, intensity, and duration) forms an essential part of viable countermeasures to cope with climate-induced risks under a rapidly warming world. Thus, this paper endeavored to explore possible non-monotonic trend components in heavy rainfall events over the Central Highlands of Vietnam by employing the Şen's innovative trend analysis (ITA) method in conjunction with the well-defined extreme rainfall indices developed by the Joint CCI/CLIVAR/JCOMM Expert Team on Climate Change Detection and Indices (ETCCDI). The outcomes show that the overall trends in most extreme rainfall indices exhibited significant increases at several stations. Moreover, the high-value subgroups of most analyzed indices (such as maximum 5-day precipitation amount (Rx5day), simple daily intensity index (SDII), very wet days (R95p), extremely wet days (R99p), number of extremely heavy precipitation days (R50mm), and consecutive dry days (CDD)) were characterized mainly by significant increasing trends, thereby implying that heavy rainfall events have become more frequent and intense over recent decades. Some stations also exposed significant increasing trend behaviors in a given extreme index within all low-, medium-, and high-value subgroups. In general, it is expected that these findings yield more insightful knowledge on rainfall extremes to local decision-makers and other stakeholders.
\end{abstract}

Keywords: Central Highlands of Vietnam, ETCCDI indices, Innovative trend analysis, Partial trend, Rainfall extremes. 
The vast majority of anthropogenic greenhouse gas emissions from fossil fuel combustion have been releasing into the Earth's atmosphere since the mid- $19^{\text {th }}$ century, which gives rise to profound changes in the Earth's climate. A recent special report released by the Intergovernmental Panel on Climate Change (IPCC) documented approximately $1.0^{\circ} \mathrm{C}\left[0.8-1.2^{\circ} \mathrm{C}\right]$ of global warming since the beginning of the industrial revolution (IPCC 2018). Moreover, human beings experience both changes in mean climate and extreme events such as hot/cold days/nights and heavy precipitation events. These moderate and rare weather and climate extremes pose a significant threat to society and biophysical systems (Dunn et al. 2020; World Meteorological Organization 2009; Zhang and Zwiers 2013). Thus, it is imperative to address trend possibilities of weather and climate extremes in the context of a warmer climate. It is advisable to utilize appropriate descriptive indices of extremes and extreme-value theory (World Meteorological Organization 2009).

From a global perspective on analyzing weather and climate extremes, a core set of 27 extremes indices for temperature and precipitation (World Meteorological Organization 2009; Zhang et al. 2011; Zhang and Zwiers 2013), defined by the Joint CCl/CLIVAR/JCOMM Expert Team on Climate Change Detection and Indices (ETCCDI), is adopted worldwide. Zhang et al. (2011) documented various evident indications of increasing (decreasing) trends in warm (cold) extremes across the globe, while heavy precipitation events tend to be more frequent and intense, which is attributable to human-induced increases in greenhouse gas concentrations (Min et al. 2011). Donat et al. (2013) and Dunn et al. (2020) developed the well-known global gridded datasets of climate extremes, namely GHCNDEX and HadEX3, respectively, which yield numerous applications in extremes analysis (such as trend identification, model evaluation, climate change detection, and attribution). Dunn et al. (2020) also substantiated several discrepancies when using 19611990 versus 1981-2010 reference periods for calculating threshold-based indices.

One of the most common themes is comparative investigations into the performance of diverse data sources in current and future assessments of extreme events. Alexander et al. (2020) conducted an intercomparison between in situ, satellite, and reanalysis products in reproducing global precipitation extremes and highlighted the applicability of satellitederived precipitation datasets, especially in ungauged or poorly gauged regions. Kim et al. (2020) demonstrated limited improvements in the Coupled Model Intercomparison Project phase 6 (CMIP6) model skills for the 27 ETCCDI climate extremes indices compared to the CMIP5 models. Lately, Sun et al. (2021) indicated significant increases in the annual maximum one-day (Rx1day) and five-day (Rx5day) precipitation at the global and continental scales, as well as in many large regions over the periods 1900-2018 and 1950-2018, thereby implying the observed intensification of extreme precipitation. Based on the state-of-the-art CMIP6 simulations under four socioeconomic development pathways, Li et al. (2021) substantiated that the frequency and intensity of hot temperature and precipitation extremes are likely to increase significantly over most of Earth's surface.

Another crucial topic under consideration is the identification of long-term temporal trends in the ETCCDI climate extremes indices. Historical changes in the extreme aspects of climate (such as intensity, duration, and frequency) play an essential role in projecting future climate change scenarios (Min et al. 2011), as well as counteracting climate-related risks to humans, ecosystems, and infrastructure (World Meteorological Organization 2009). Over the last few decades, there has been a proliferation of case studies that employ parametric and non-parametric statistical trend tests for analyzing past changes in extremes indices. Dimri (2019) applied the modified Mann-Kendall (MK) test and Sen's slope estimator to compare regional and seasonal trends in eight extreme temperature indices derived from the ERA-Interim and IDM datasets over India. Dookie et al. (2019) utilized the least-squares regression and Student's $t$-test to demonstrate local patterns in eleven temperature and ten precipitation indices over two Caribbean small islands. García-Cueto et al. (2019) applied the MK and Sen's slope tests in 14 ETCCDI climate extremes indices to indicate changing climate conditions over some urban areas in Mexico. Murara et al. (2019) also employed the linear least square method and MK test to estimate the magnitude and statistical significance of trends in ten extreme precipitation indices in the Itajaí river basin (Brazil). Qian et al. (2019) applied various parametric and non-parametric methods (such as ordinary and refined least squares regression, classical and modified MK, and Sen's slope) in eight extreme temperature indices derived from observational and gridded datasets across China. Qian et al. (2019) also emphasized the prime importance of nonGaussian and serial independent assumptions when applying classical parametric and non-parametric methods to analyze trends in climate extremes indices. Costa et al. (2020) employed linear regression and sequential MK test to estimate annual trends in ETCCDI climate extremes indices over northeast Brazil. Venkata Rao et al. (2020) explored spatiotemporal changes in nine extreme rainfall indices by utilizing Sen's slope, classical MK, and its modifications over two flood-prone basins in eastern India at three time periods (i.e., long-term (1901-2018), pre-1950, and post-1950). 
In Vietnam, the characteristics of climate extremes are assessed comprehensively at the national and sub-regional scales. Ho et al. (2011) delved into the past and future trends in hot days, cold nights, and heavy rainfall days over seven climatic sub-regions in Vietnam based on observed records and Regional Climate Model (RCM) outputs. Ngo-Duc et al. (2014) further applied Student's paired $t$-test, Sen's slope, and MK test to explore projected changes in the annual maximum value of daily maximum temperature (TXx), the annual minimum value of daily minimum temperature (TNn), and Rx1day over Vietnam based on the outputs of three RCMs. At the city scale, Quan et al. (2021) presented a wellconducted investigation into the statistical strength, stability, and magnitude of historical trends in seven extreme rainfall indices in Ho Chi Minh City (Vietnam) by employing Sen's slope and MK test in conjunction with the trend-free prewhitening procedure. Khoi et al. (2021) further applied the same trend analysis methods to explore future changes in the spatio-temporal patterns of extreme rainfall indices over Ho Chi Minh City (Vietnam) based on the statistically downscaled climate data.

It is acknowledged that most previous trend search studies on climate extremes were carried out mainly through parametric and non-parametric approaches such as linear regression, Sen's slope estimator, classical and modified MK tests. These commonly used statistical methods need to comply with some assumptions such as normal distribution, serial independence, and sufficient length of observed records. In practice, almost all hydro-meteoro-climatological data are serially correlated, which will lead to misinterpretation of trend existence in a given time series (Almazroui and Şen 2020; von Storch 1995). Qian et al. (2019) also indicated that most climate extremes indices are unlikely to follow a Gaussian distribution as well as serial independence. Additionally, these aforementioned methods identify only overall linear or monotonic trends within a given considered period. On the other hand, an innovative trend analysis (ITA) methodology, originated by Şen $(2012,2014,2017)$, can be employed to identify temporal trends in a given time series without considering any restrictive assumptions Almazroui and Şen (2020); Şen (2012). This cutting-edge method also yields more detailed information about trend behaviors such as non-monotonic trends and sub-trends in a given time series (Dabanlı et al. 2016; Elouissi et al. 2016; Şen 2012). Recently, the ITA method was applied successfully to identify trend possibilities of conventional hydro-meteorological variables (Dabanlı et al. 2016; Elouissi et al. 2016; Öztopal and Şen 2017), as well as derived indices such as Standardized Precipitation Index (Caloiero 2018; Danandeh Mehr and Vaheddoost 2020; Phuong et al. 2021; Yilmaz 2019), Standardized Precipitation Evapotranspiration Index (Danandeh Mehr and Vaheddoost 2020), and Effective Drought Index (Malik et al. 2020).

In general, applying the ITA method in climate extremes indices can yield more insights into the changing character of climate extremes. Thus, the present study aimed to delve deeper into the overall and partial trends in extreme rainfall events over the Central Highlands of Vietnam by employing the ITA method in conjunction with ten ETCCDI extreme rainfall indices. It is expected that understanding temporal trends in low- and high-value subgroups of extreme rainfall indices could contribute more scientific merits to local decision-makers and other stakeholders to cope with climate-related risks under a changing climate.

\section{Materials and Methods}

\subsection{Study Area}

The selected study area is the Central Highlands of Vietnam (Fig. 1), which is a mountainous region with elevation ranging considerably between 100 and 2400 meters above mean sea level. The Central Highlands, covering an area of approximately $54,508 \mathrm{~km}^{2}$ (accounting for around 16.5\% of the total area of Vietnam), lies approximately between the latitudes $11^{\circ} 20^{\prime} \mathrm{N}-15^{\circ} 40^{\prime} \mathrm{N}$, and the longitudes $107^{\circ} 20^{\prime} \mathrm{E}-109^{\circ} 00^{\prime} \mathrm{E}$. In 2020 , the number of inhabitants was around 5.9 million persons (accounting for nearly $6.1 \%$ of the total population of Vietnam). Diverse ethnic groups are living in the Central Highlands, and the socioeconomic conditions are relatively low compared to other regions in Vietnam.

There are 12 meteorological stations located quite proportionally to the whole extent of the Central Highlands (Fig. 1). It is noting that the available rainfall records cover 38-year (1982-2019) to 59-year (1961-2019) periods depending on certain meteorological stations. According to the well-known world map of the Köppen-Geiger climate classification proposed by Peel et al. (2007), the general climate of the Central Highlands is categorized mainly as tropical savannah (Aw) climate. The average annual temperatures in the Central Highlands are approximately $18.0^{\circ} \mathrm{C}-25.9^{\circ} \mathrm{C}$, which is significantly lower than the temperatures in surrounding climatic sub-regions (Ho et al. 2011). Additionally, there are two distinct seasons, namely dry and rainy seasons, in the Central Highlands. Rainfall during the rainy season (May - October) contributes mainly to the total amount of annual rainfall, varying from around 1200 to $2700 \mathrm{~mm}$. Ho et al. (2011) documented a coincidence of the rainy season in the Central Highlands and the active phase of the Asian monsoon. 
(a) Vietnam

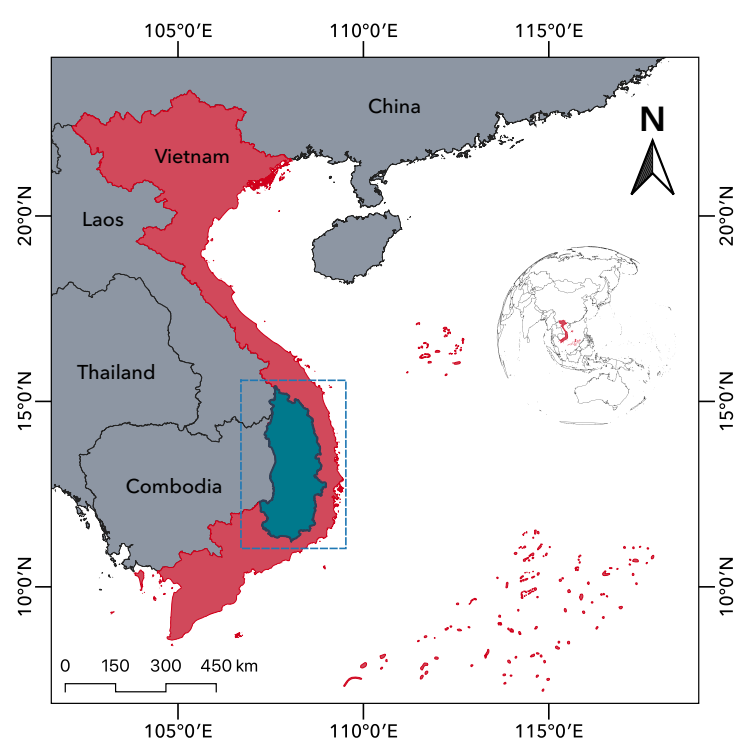

(b) Central Highlands

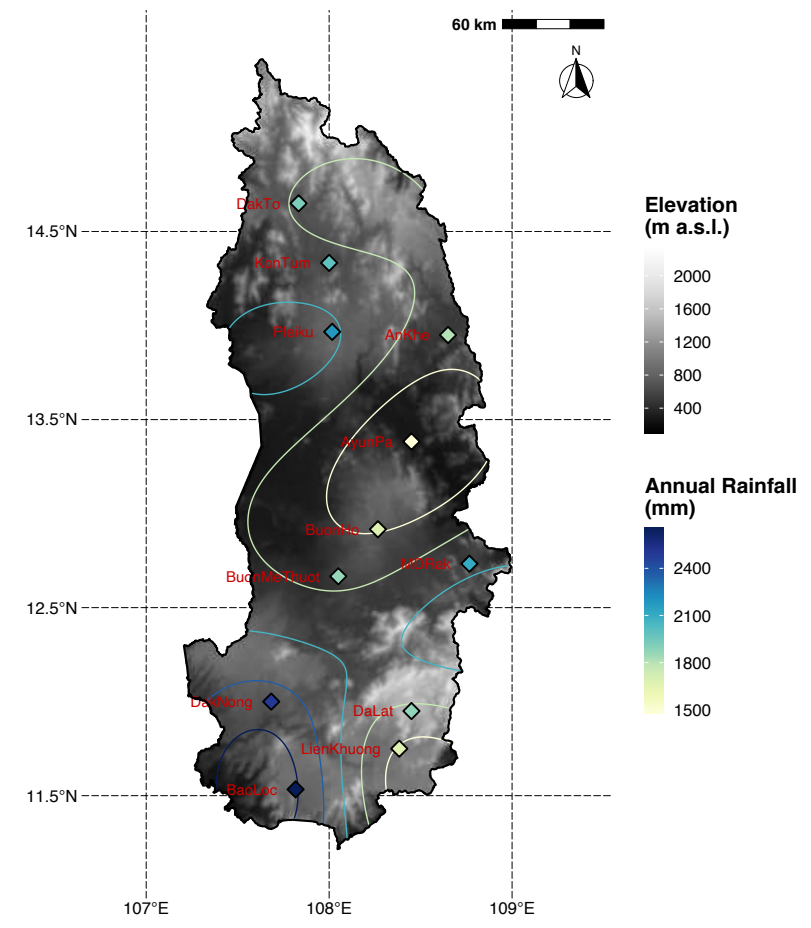

Fig. 1 Geographical location of the Central Highlands of Vietnam. The grey color palette stands for elevation. The yellowgreen-blue color palette stands for long-term means of annual rainfall represented by contour lines and diamond-filled symbols

\subsection{Extreme Precipitation Indices}

Moderate extremes typically occur at least once or several times every year (World Meteorological Organization 2009; Zhang et al. 2011). It is recommended to employ an internationally coordinated core set of 27 ETCCDI indices to comprehend potential changes in the characteristics of moderate temperature and precipitation extremes (such as frequency, intensity, and duration) (World Meteorological Organization 2009; Zhang et al. 2011; Zhang and Zwiers 2013). The ETCCDI indices, derived from daily weather data, were defined to facilitate many difficulties in understanding past, current, and future changes in weather and climate extremes. Additionally, utilizing agreed-upon indices makes it possible to investigate comparative studies of the characteristics of extremes in different climatic regions across the globe and draw out a global perspective on climate extremes accordingly (Zhang et al. 2011).

In essence, the ETCCDI indices can be classified into three types (Zhang et al. 2011; Zhang and Zwiers 2013). The first one is absolute extremes quantifying the monthly/annual maximum/minimum values of daily temperature and maximum values of daily precipitation amounts, which is substantially conducive to a wide range of engineering fields. The second and third types are day-count indices with fixed and percentile thresholds, respectively. The day-count indices with fixed thresholds are more suitable for impact studies on health, hydrology, and agriculture. Meanwhile, the daycount indices based on percentile thresholds, expressing anomalies relative to the local climate, allow for meaningful spatial comparisons of different regions with different climate conditions.

The present study analyzed ten extreme precipitation indices as outlined in Table 1 . These indices were calculated on an annual basis. It is noting that R50mm is a user-defined index. The user-defined threshold was set to $50 \mathrm{~mm}$ since this extreme threshold is currently used by the Vietnam Meteorological and Hydrological Administration. The R50mm was also analyzed by Endo et al. (2009); Ngo-Duc et al. (2014); Tangang et al. (2018). For the percentile-based indices, it is necessary to determine a reference period explicitly. Based on the availability of meteorological datasets, this study calculated percentile-based indices using a 1981-2010 reference period, which is recommended by World Meteorological Organization (2017) and used by Dunn et al. (2020). This study utilized the R programming language (Ihaka and Gentleman 1996; R Core Team 2021) in conjunction with the "climdex.pcic" package (David Bronaugh for the Pacific Climate Impacts Consortium 2020) for extreme indices calculation and the "tidyverse" package (Wickham et al. 2019) for data manipulation and visualization. 
Table 1 List of the ETCCDI extreme precipitation indices employed in this study

\begin{tabular}{|c|c|c|c|c|}
\hline $\begin{array}{l}\text { Extreme } \\
\text { Aspects }\end{array}$ & ID & Indicator Name & Indicator Definitions & Units \\
\hline \multirow{5}{*}{ Intensity } & Rx1day & Max 1-day precipitation amount & Monthly maximum 1-day precipitation & $\mathrm{mm}$ \\
\hline & Rx5day & Max 5-day precipitation amount & $\begin{array}{l}\text { Monthly maximum consecutive 5-day } \\
\text { precipitation }\end{array}$ & $\mathrm{mm}$ \\
\hline & SDII & Simple daily intensity index & $\begin{array}{l}\text { The ratio of annual total precipitation to } \\
\text { the number of wet days ( } \geq 1 \mathrm{~mm})\end{array}$ & $\mathrm{mm} /$ day \\
\hline & $\mathrm{R} 95 \mathrm{p}$ & Very wet days & $\begin{array}{l}\text { Annual total precipitation from days }>95^{\text {th }} \\
\text { percentile }\end{array}$ & $\mathrm{mm}$ \\
\hline & R99p & Extremely wet days & $\begin{array}{l}\text { Annual total precipitation from days }>99^{\text {th }} \\
\text { percentile }\end{array}$ & $\mathrm{mm}$ \\
\hline \multirow{3}{*}{ Frequency } & $\mathrm{R} 10 \mathrm{~mm}$ & $\begin{array}{l}\text { Number of heavy precipitation } \\
\text { days }\end{array}$ & Annual count when precipitation $\geq 10 \mathrm{~mm}$ & days \\
\hline & $\mathrm{R} 20 \mathrm{~mm}$ & $\begin{array}{l}\text { Number of very heavy } \\
\text { precipitation days }\end{array}$ & Annual count when precipitation $\geq 20 \mathrm{~mm}$ & days \\
\hline & $\mathrm{R} 50 \mathrm{~mm}$ & $\begin{array}{l}\text { Number of extremely heavy } \\
\text { precipitation days }\end{array}$ & Annual count when precipitation $\geq 50 \mathrm{~mm}$ & days \\
\hline \multirow{2}{*}{ Duration } & CDD & Consecutive dry days & $\begin{array}{l}\text { Maximum number of consecutive days } \\
\text { when precipitation days }<1 \mathrm{~mm}\end{array}$ & days \\
\hline & CWD & Consecutive wet days & $\begin{array}{l}\text { Maximum number of consecutive days } \\
\text { when precipitation days } \geq 1 \mathrm{~mm}\end{array}$ & days \\
\hline
\end{tabular}

\subsection{Innovative Trend Analysis (ITA) Methodology}

Şen $(2012,2014,2017)$ developed an innovative trend analysis methodology, which is fundamentally based on constructing a scatter plot of a set of subseries derived from a given time series on a Cartesian coordinate system. Furthermore, various improved versions of the ITA method were proposed to enhance visual properties and assess statistical significance (Phuong et al. 2021). In comparison with the well-known (non)parametric statistical trend tests such as linear regression and MK methods, the ITA method does not require any restrictive assumptions such as normality and serial independence (Şen 2012, 2014). Another advantage of the ITA method is that this method can be applied to a small sample (e.g., ten observations), while the other classical approaches necessitate at least 30 data records (Almazroui and Şen 2020). Especially, non-monotonic trends (i.e., the composition of various trend components) in a given hydrometeorological time series can be detected by the ITA method (Şen 2012, 2014). Specifically, the ITA method can yield more detailed information about the overall and partial trends based on deliberate categorization.

Fig. 2 depicts a typical innovative trend plot. A step-by-step procedure to implement the ITA method was described clearly by McCuen (2018); Öztopal and Şen (2017). In particular, the first step is to divide the original time series into two (or more) equal subseries and then sort each subseries in ascending order after preparing well-founded datasets. Then, the first half subseries is plotted on the abscissa axis against the second one on the ordinate axis. The final step is to draw the $1: 1\left(45^{\circ}\right)$ straight line and $\pm 10 \%$ lines on the Cartesian coordinate system. Theoretically, the $1: 1\left(45^{\circ}\right)$ straight line divides the ITA plot into two equal regions (Fig. 2). The upper/lower triangular areas indicate increasing/decreasing trends, while the $1: 1\left(45^{\circ}\right)$ straight line corresponds to trend-free cases. Additionally, Şen $(2012,2014)$ substantiated that the trend slope tends to get stronger when the scatter points fall far from the $1: 1\left(45^{\circ}\right)$ straight line. To yield more quantitative interpretations, one can calculate the trend slope developed by Şen (2017) according to the following expression:

$$
s=\frac{2\left(\bar{y}_{2}-\bar{y}_{1}\right)}{n}
$$


where $s$ is the ITA trend slope. $n$ is the sample length. $\bar{y}_{1}$ and $\bar{y}_{2}$ are the arithmetic averages of the first and second halves of a given time series, respectively.
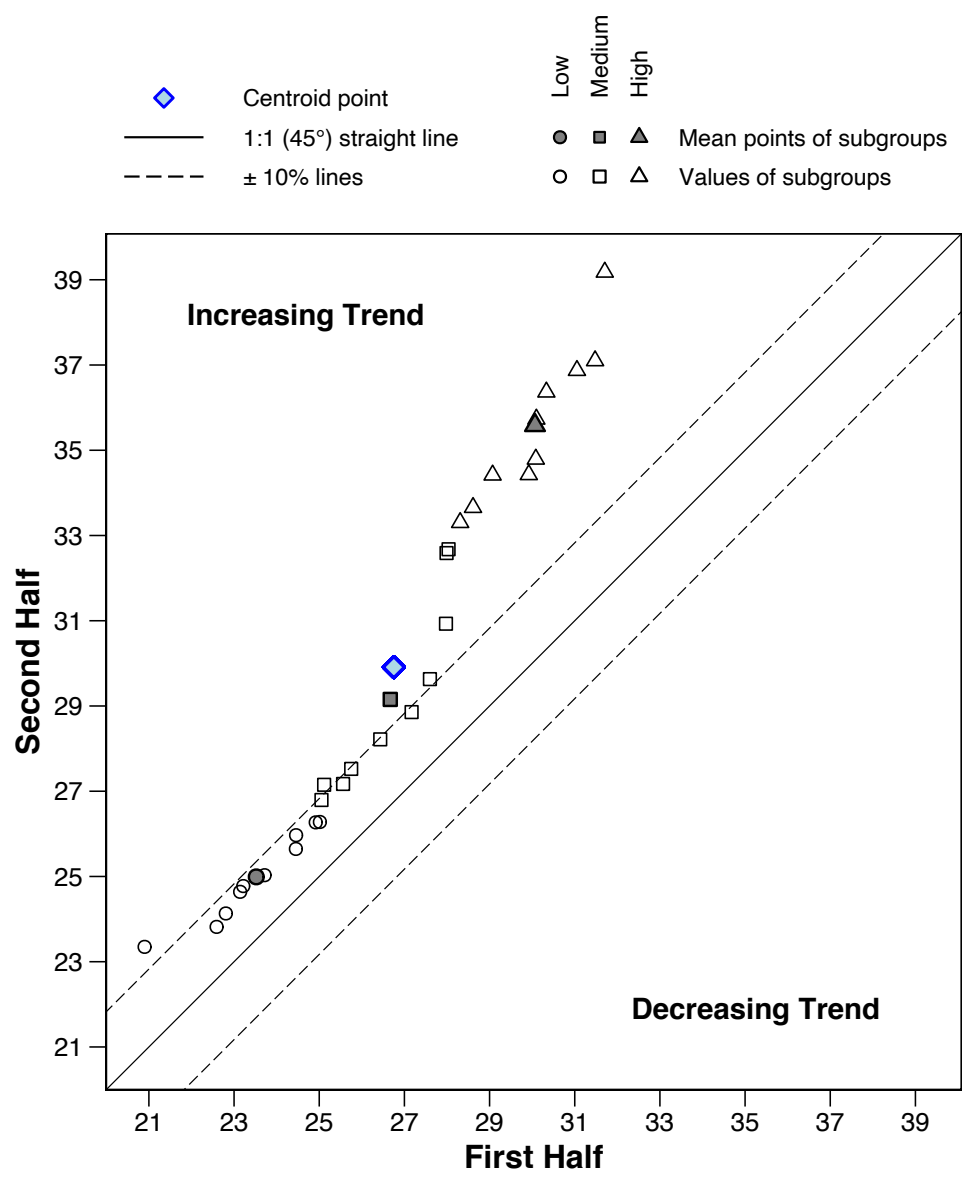

Fig. 2 Illustration of a typical ITA trend plot for a synthetic time series

Temporal trend possibilities of ten ETCCDI extreme rainfall indices over the Central Highlands of Vietnam were explored by employing the ITA method, as illustrated in Fig. 3 - Fig. 12. In these figures, the blue diamond symbols are centroid points used for indicating over trends, while the grey-filled circle, square, and triangle symbols are mean points of low-, medium-, and high-value clusters, respectively, used for identifying corresponding sub-trends as suggested by Dabanli et al. (2016).

Fig. 3 and Fig. 4 depict the results of overall and partial trend identification of the annual maximum amount of precipitation accumulated over one day (Rx1day) and five consecutive days (Rx5day), respectively. The overall trends in Rx1day and Rx5day have neutral behaviors at most stations, accounting for 7 out of 12 stations. The increasing trends in Rx1day were obtained in four stations (i.e., Kon Tum, Buon Me Thuot, Dak Nong, and Bao Loc), with the estimated ITA trend slope varying around 0.73-0.89 mm/year, while the Ayun Pa station was the only one responsible for the significant declining trend at the rate of approximately $-1.74 \mathrm{~mm} /$ year. In comparison, three stations (i.e., Kon Tum, Buon Me Thuot, and Bao Loc) also experienced significant increases in Rx5day at the rate of around 1.17-2.38 mm/year, while significant decreases were found in Dak To and Ayun Pa stations, with the estimated ITA trend slope of approximately $-1.5 \mathrm{~mm} / \mathrm{year}$.

Moreover, Fig. 3 and Fig. 4 delineate several partial trend patterns in Rx1day and Rx5day. The low- and mediumvalue subgroups were characterized mainly by trend-free behaviors at most stations, accounting for 8-10 out of 12 stations. Concerning the high-value cluster, four stations (i.e., An Khe, Buon Me Thuot, Dak Nong, and Bao Loc) exhibited significant increases in Rx1day, and six stations (i.e., Kon Tum, Buon Ho, Buon Me Thuot, Dak Nong, Da Lat, and Bao Loc) exposed significant increases in Rx5day. It is noting that the Kon Tum station experienced significant increases in Rx5day within all subgroups. The findings of significant increases in the high-value subgroups indicated that the absolute extremes have intensified over recent decades whether the overall trends or the low- and medium-value clusters were significant or not. 

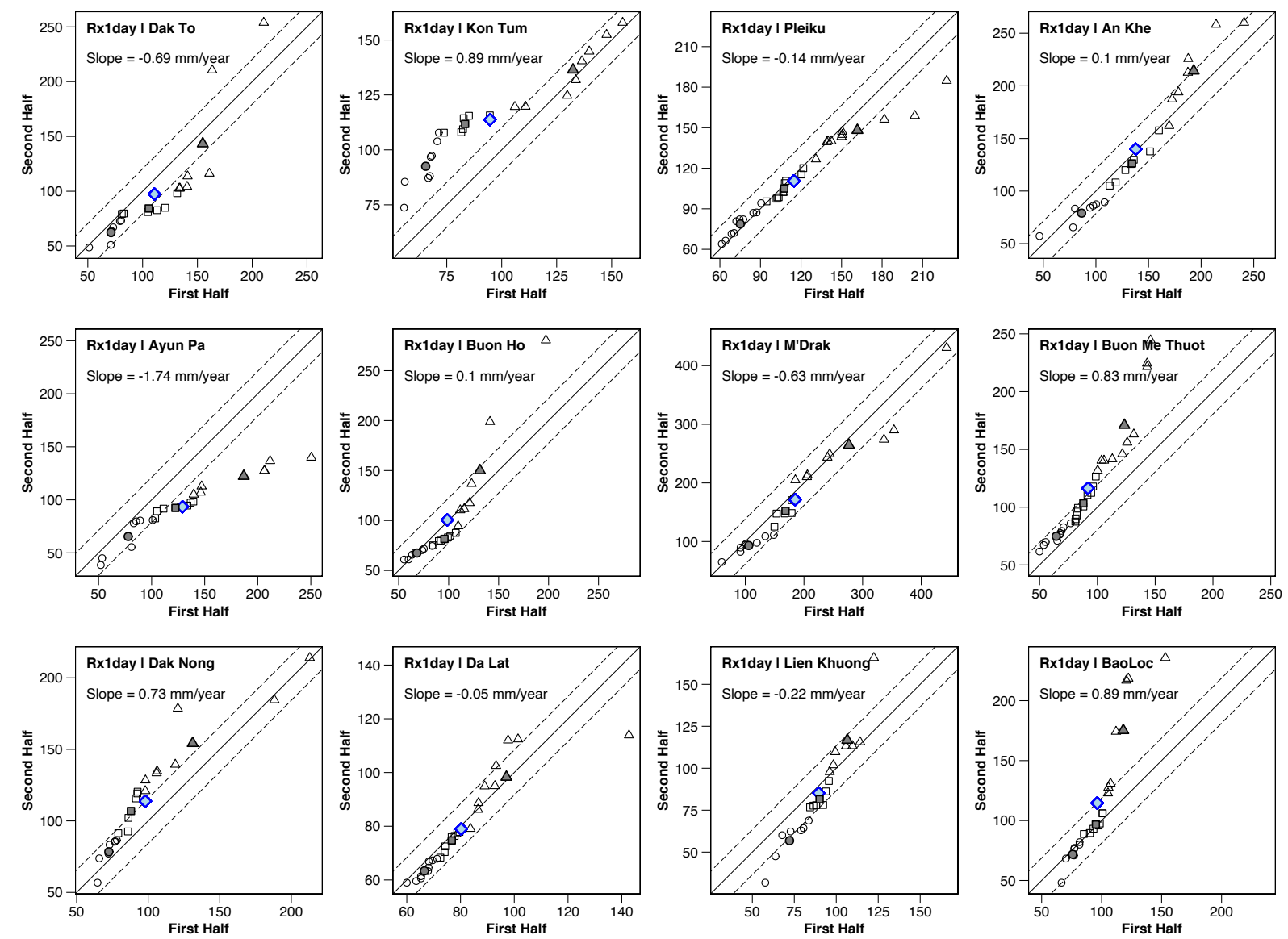

Fig. 3 Innovative trend plots for Rx1day. The ITA trend slope is depicted in the top-left corner of each panel
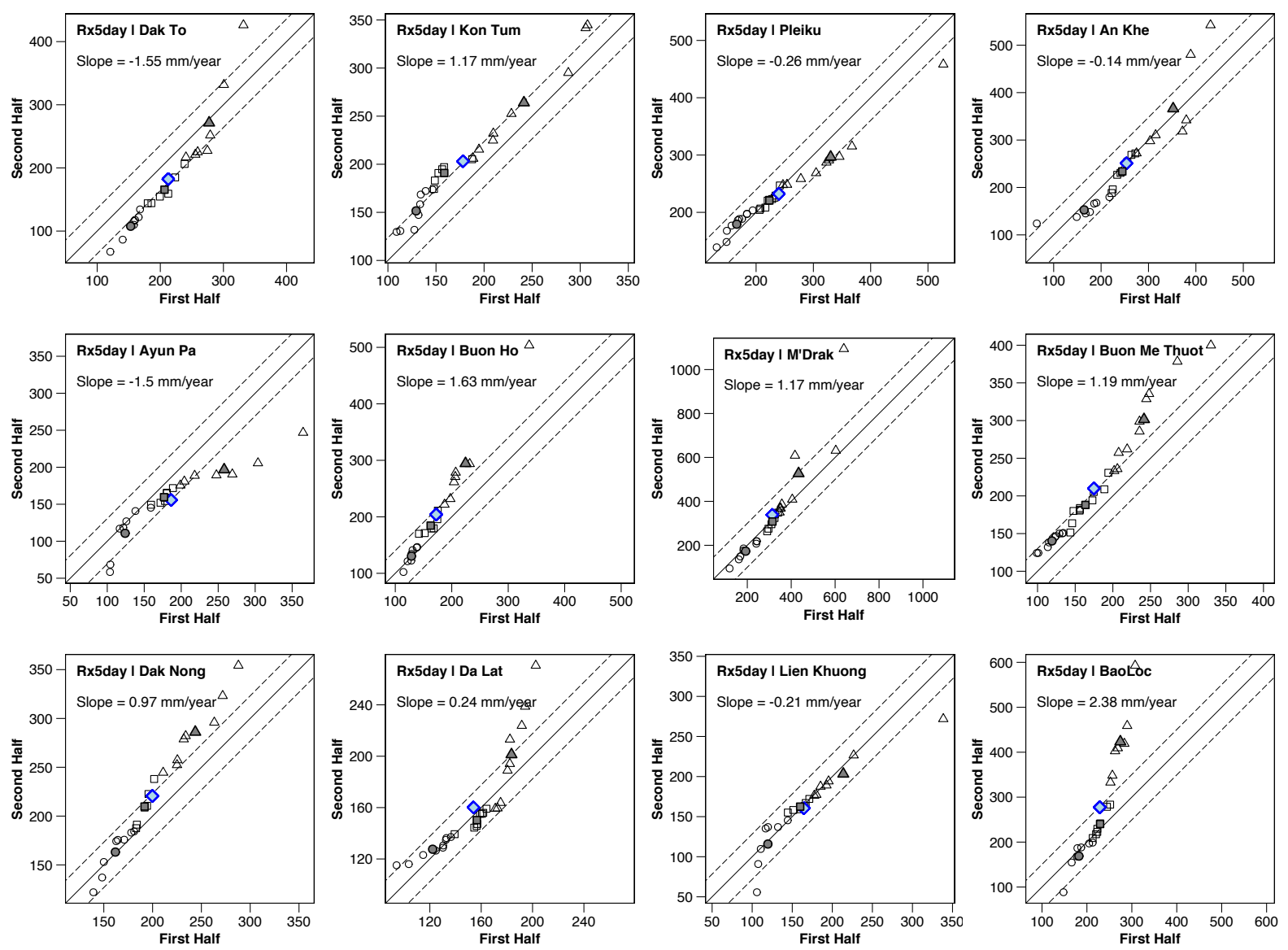

Fig. 4 As in Figure 3, but for Rx5day 
Turning to the simple daily intensity index (SDII), Fig. 5 shows that more than half of the analyzed stations exhibited significant increases (including Kon Tum, Pleiku, Buon Ho, M'Drak, Buon Me Thuot, Dak Nong, and Bao Loc). The magnitude of these upward trends was estimated approximately from 0.04 to $0.17 \mathrm{~mm} /$ day/year. Concerning sub-trend interpretations, it is discernible that the majority of scatter points in high-value SDII subgroups at four stations (i.e., Buon Ho, M'Drak, Dak Nong, and Bao Loc) fall father to the 1:1 (45 ) straight line compared to the low- and medium-value clusters, thereby indicating higher increasing trends in high-value subgroups. Moreover, the Bao Loc station exhibited increasing trend behaviors within all subgroups.
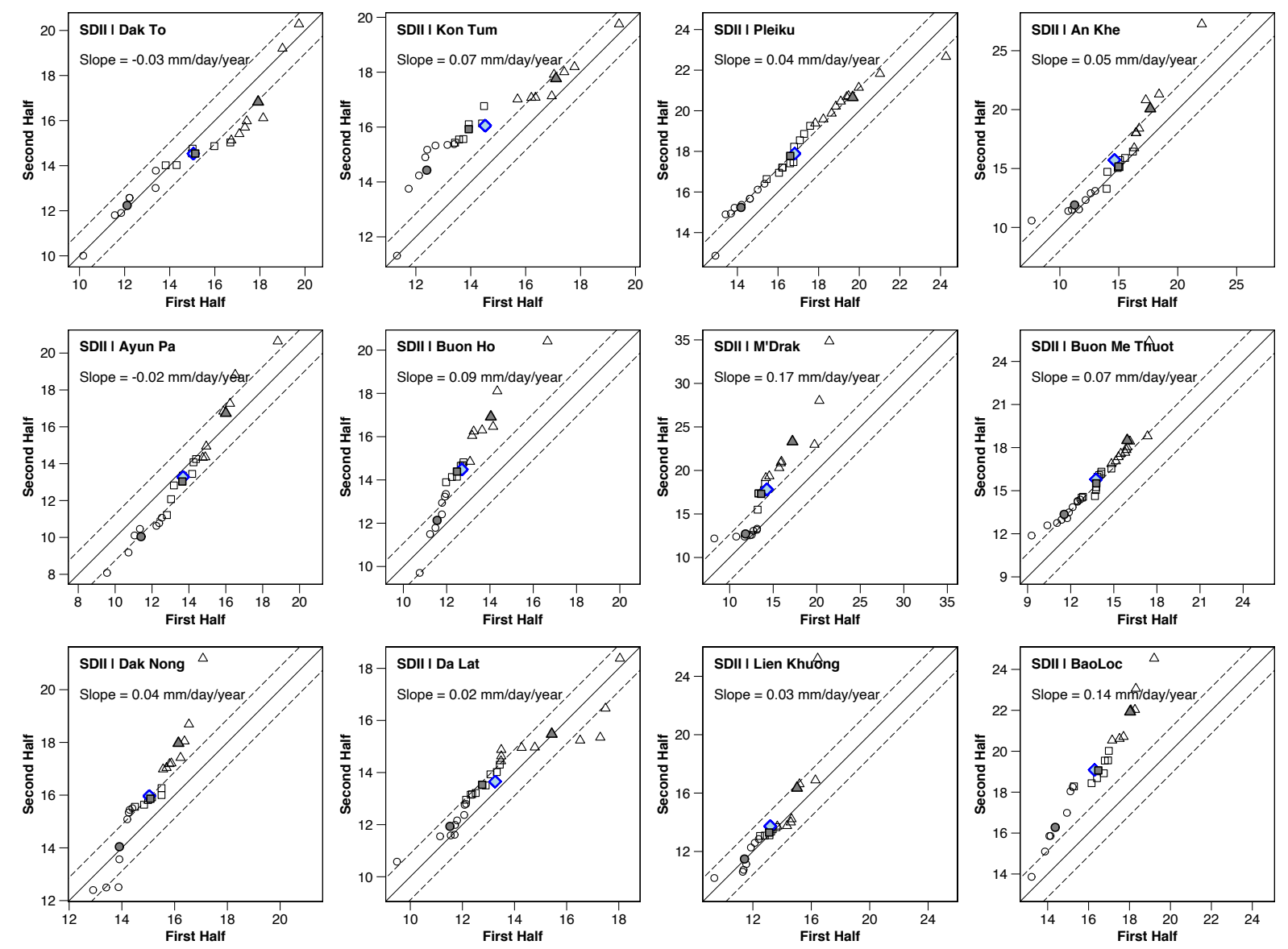

Fig. 5 As in Figure 3, but for SDII

Fig. 6 and Fig. 7 represent temporal trend possibilities in the very wet days (R95p) and extremely wet days (R99p), respectively. As expected, the R95p and R99p exposed the same overall and partial trend patterns over the study area. In particular, 7 out of 12 stations exhibited almost trendless behaviors. Meanwhile, significant increases were found in three stations (i.e., Kon Tum, Buon Me Thuot, and Dak Nong), with the estimated ITA trend slopes varying from 4.3-9.4 $\mathrm{mm} /$ year as for R95p and from 2.3-6.1 mm/year as for R99p. Conversely, significant decreases at the rate of approximately from -5.0 to $-6.5 \mathrm{~mm} /$ year as for R95p, and -2.8 to $-4.7 \mathrm{~mm} /$ year as for R99p were obtained in two stations (i.e., Dak To and Ayun Pa).

Fig. 6 and Fig. 7 further portray potential trends in low-, medium-, and high-value R95p and R99p subgroups. In particular, there is high domination of neutral trends in low- and medium-value clusters as for both R95p and R99p. Meanwhile, the high-value subgroups were dominated mainly by significant upward trends. Eight stations (i.e., Kon Tum, An Khe, Buon Ho, M’Drak, Buon Me Thuot, Dak Nong, Da Lat, and Bao Loc) experienced significant increases in R95p, and six stations (i.e., Kon Tum, An Khe, M'Drak, Buon Me Thuot, Dak Nong, and Bao Loc) exhibited significant increases in R99p. Moreover, the Kon Tum station was the only one responsible for significant increases in R95p and R99p within all clusters. In general, the vast majority of significant increasing trends in high-value subgroups imply that these percentile-based indices have become more intense over recent decades. 

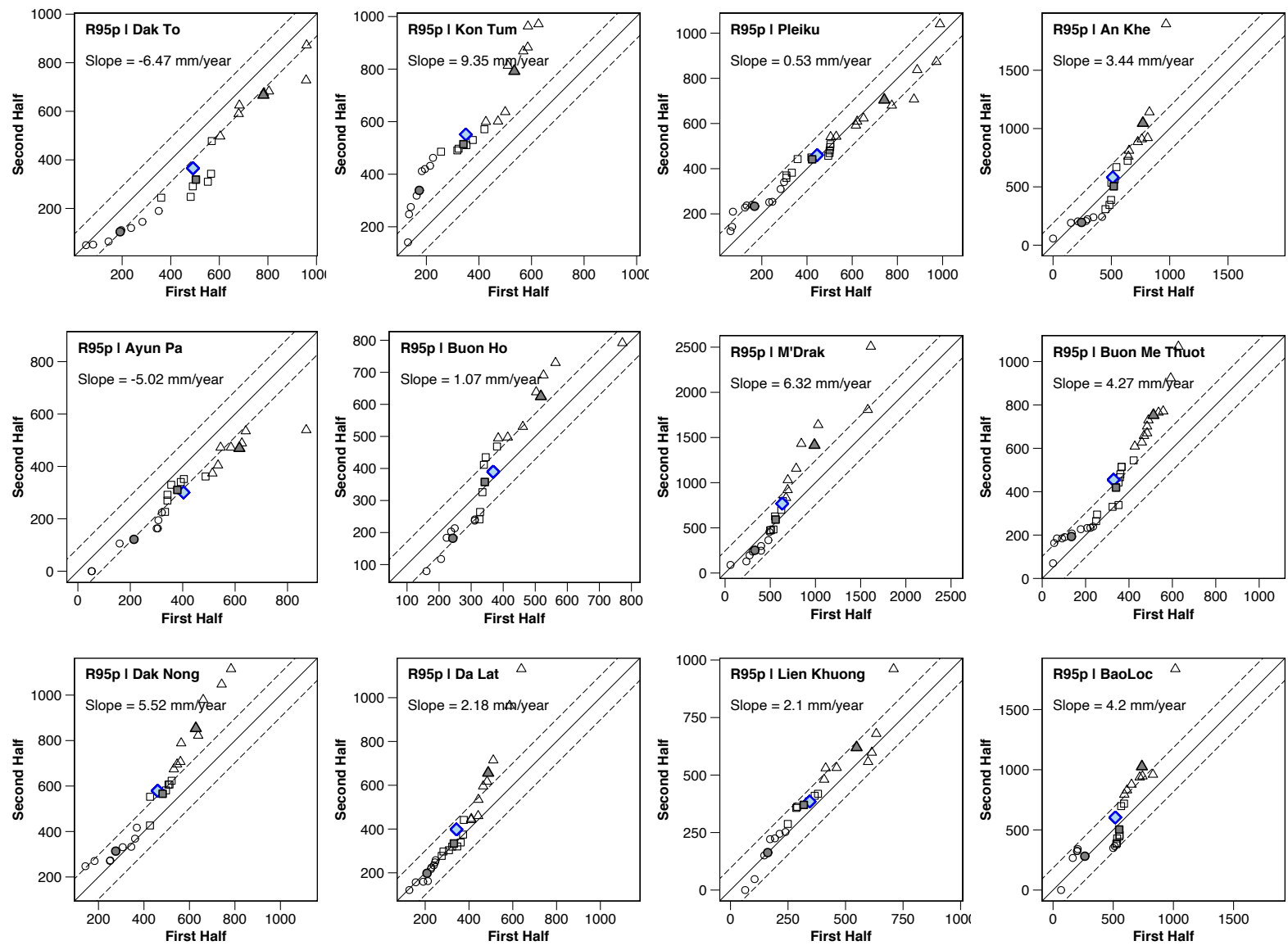

Fig. 6 As in Figure 3, but for R95p
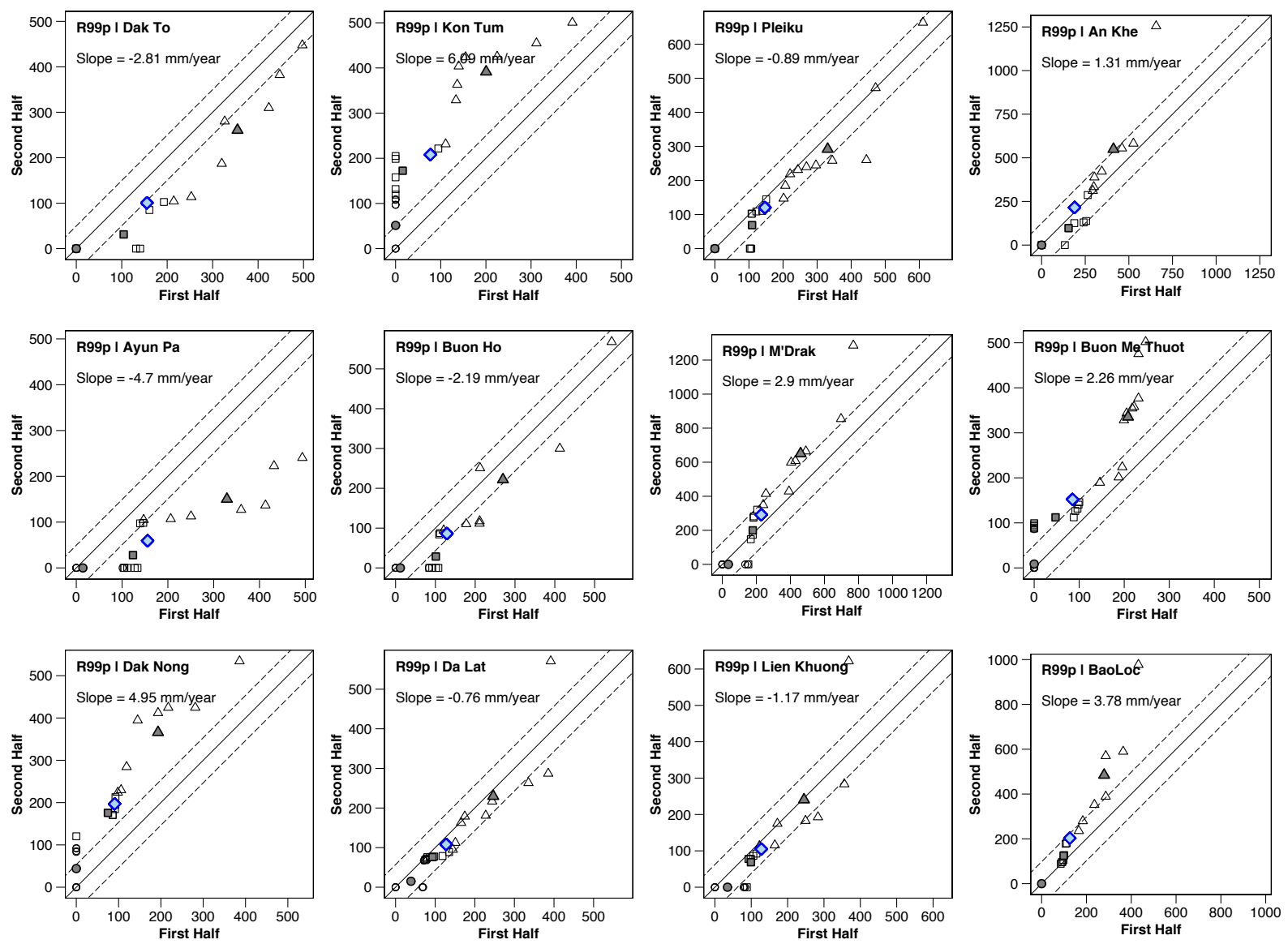

Fig. 7 As in Figure 3, but for R99p 
Turning to the number of days per year with rainfall amount $\geq 10 \mathrm{~mm}(\mathrm{R} 10 \mathrm{~mm}), \geq 20 \mathrm{~mm}(\mathrm{R} 20 \mathrm{~mm})$, and $\geq 50$ mm (R50mm), Fig. 8 - Fig. 10 show that few stations exhibited significant increases. In particular, the overall increasing trends in R20mm were found in three stations (i.e., Kon Tum, An Khe, and M'Drak), with the estimated ITA slopes ranging approximately from 0.14-0.24 days/year. Similarly, three stations (i.e., Kon Tum, Buon Me Thuot, and Dak Nong) exhibited significant increases in R50mm at the rate of around $0.05-0.10$ days/year. Meanwhile, there is high domination of neutral and decreasing trends in R10mm.

Fig. 8 - Fig. 10 also reveal that the low- and medium-value subgroups of R10mm, R20mm, and R50mm were characterized mainly by trendless and decreasing behaviors. Concerning the high-value subgroups, there were two stations (i.e., An Khe and M'Drak) exhibiting significant increases in R10mm, and five stations (i.e., Kon Tum, An Khe, M'Drak, Dak Nong, and Bao Loc) experiencing significant increases in R20mm. Moreover, most stations exposed significant upward trends in R50mm, accounting for 8 out of 12 stations such as Kon Tum, An Khe, Buon Ho, M'Drak, Buon Me Thuot, Dak Nong, Da Lat, and Bao Loc. It is worth noting that the Kon Tum station demonstrated increasing trend behaviors irrespective of low-, medium-, or high-value subgroups. In general, these outcomes indicate that the very heavy rainfall days (R20mm) and extremely heavy rainfall days (R50mm) have occurred more frequently during the study period.
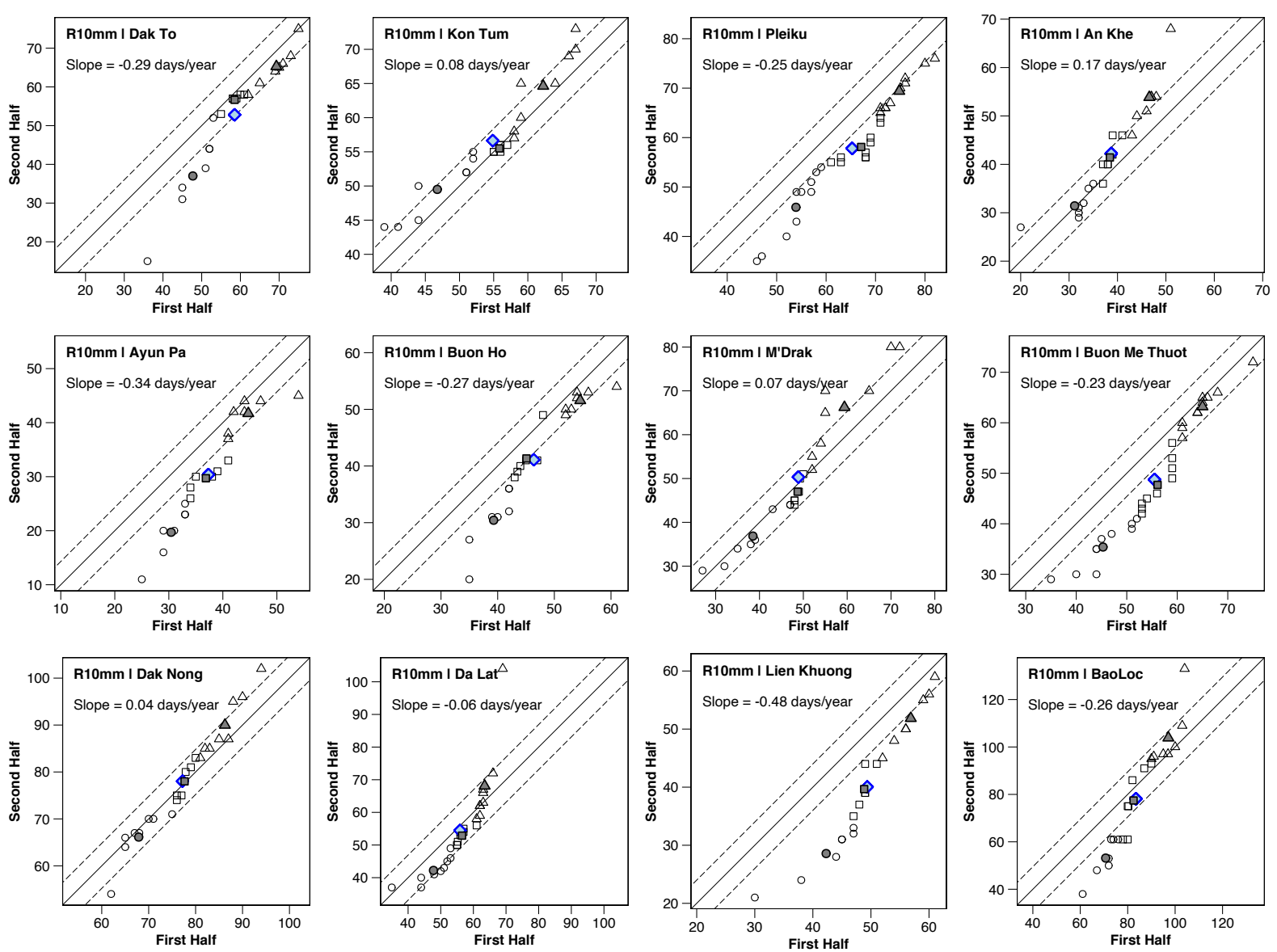

Fig. 8 As in Figure 3, but for R10mm 

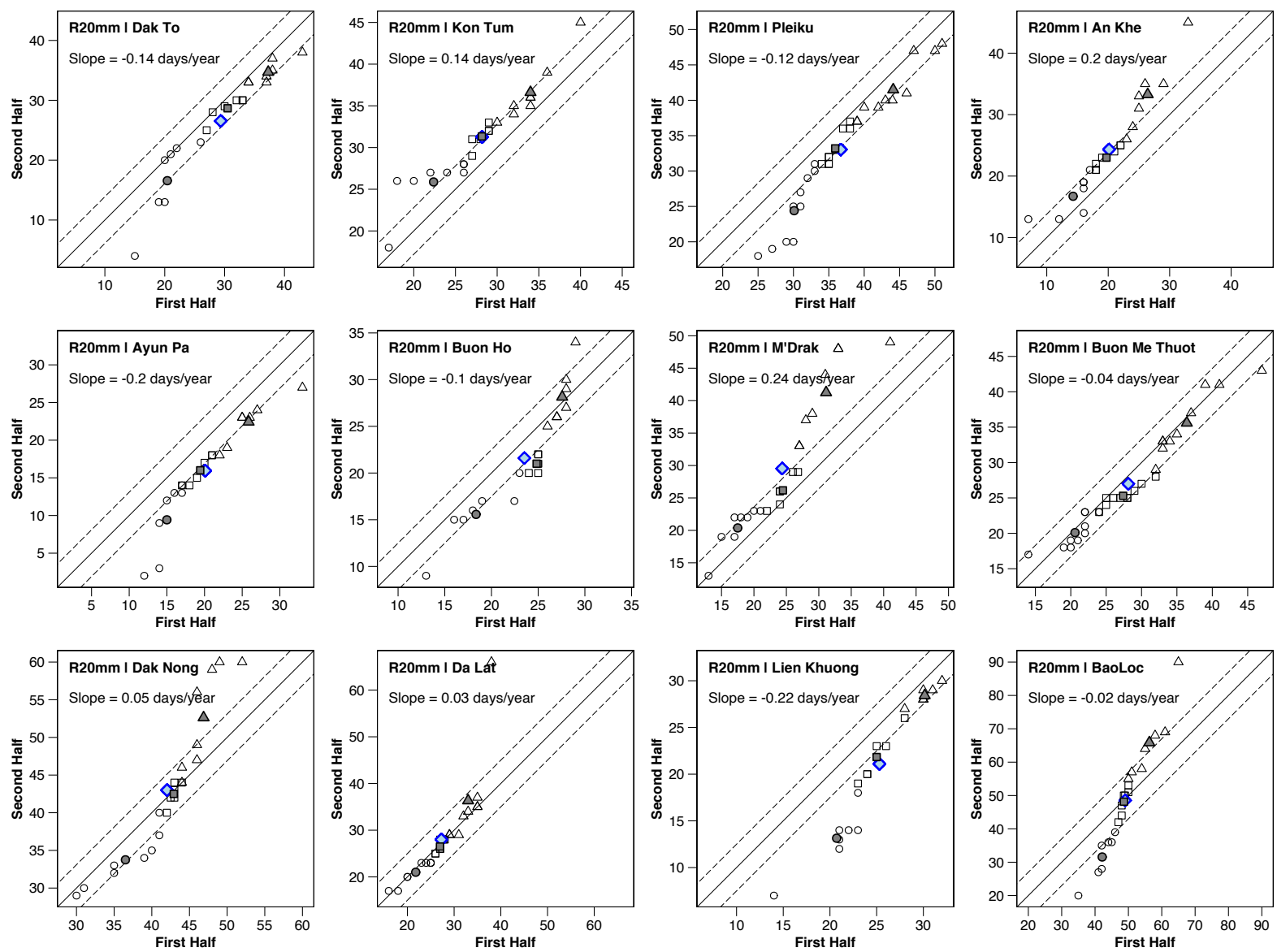

274 Fig. 9 As in Figure 3, but for R20mm
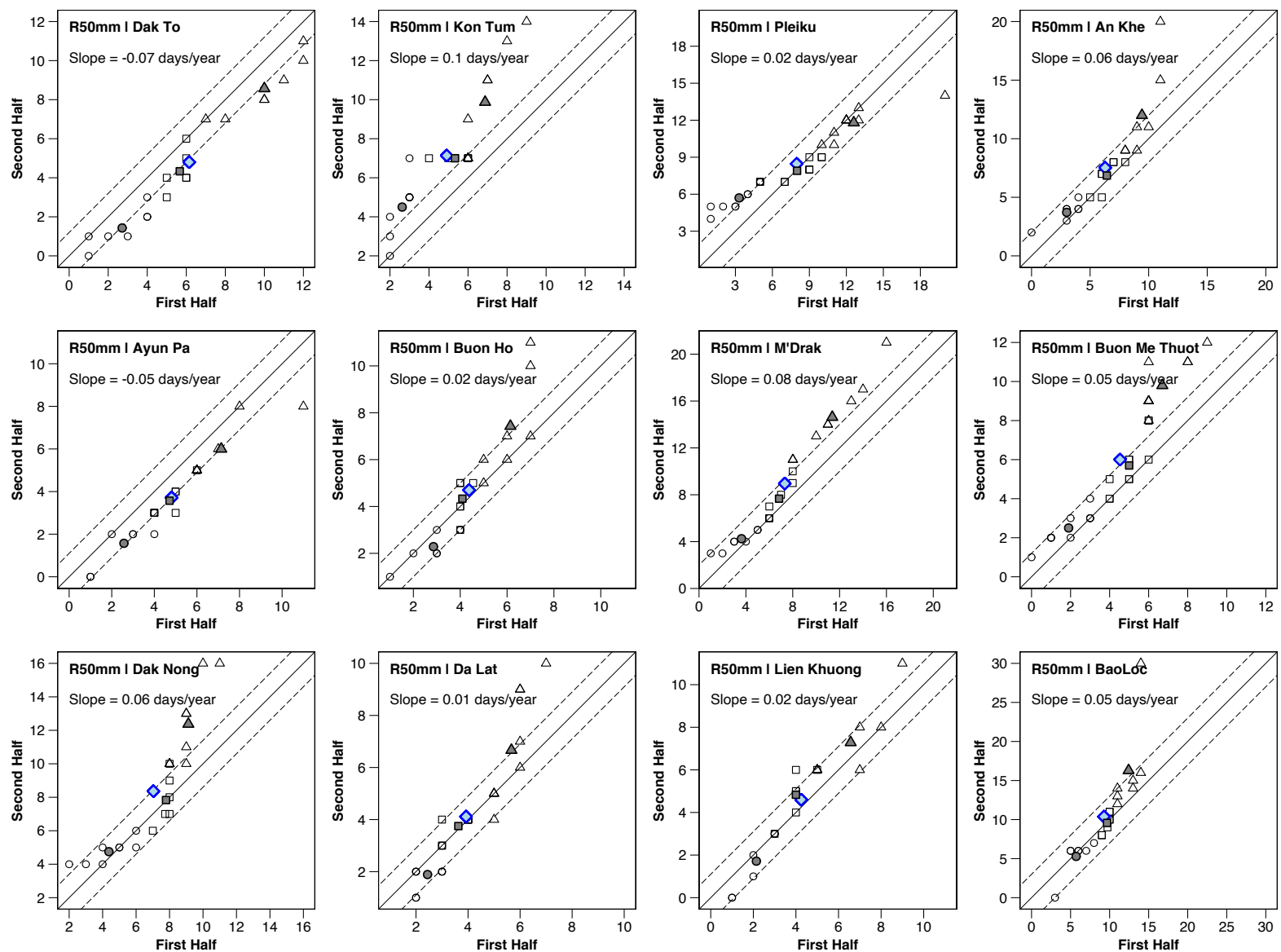

Fig. 10 As in Figure 3, but for R50mm 

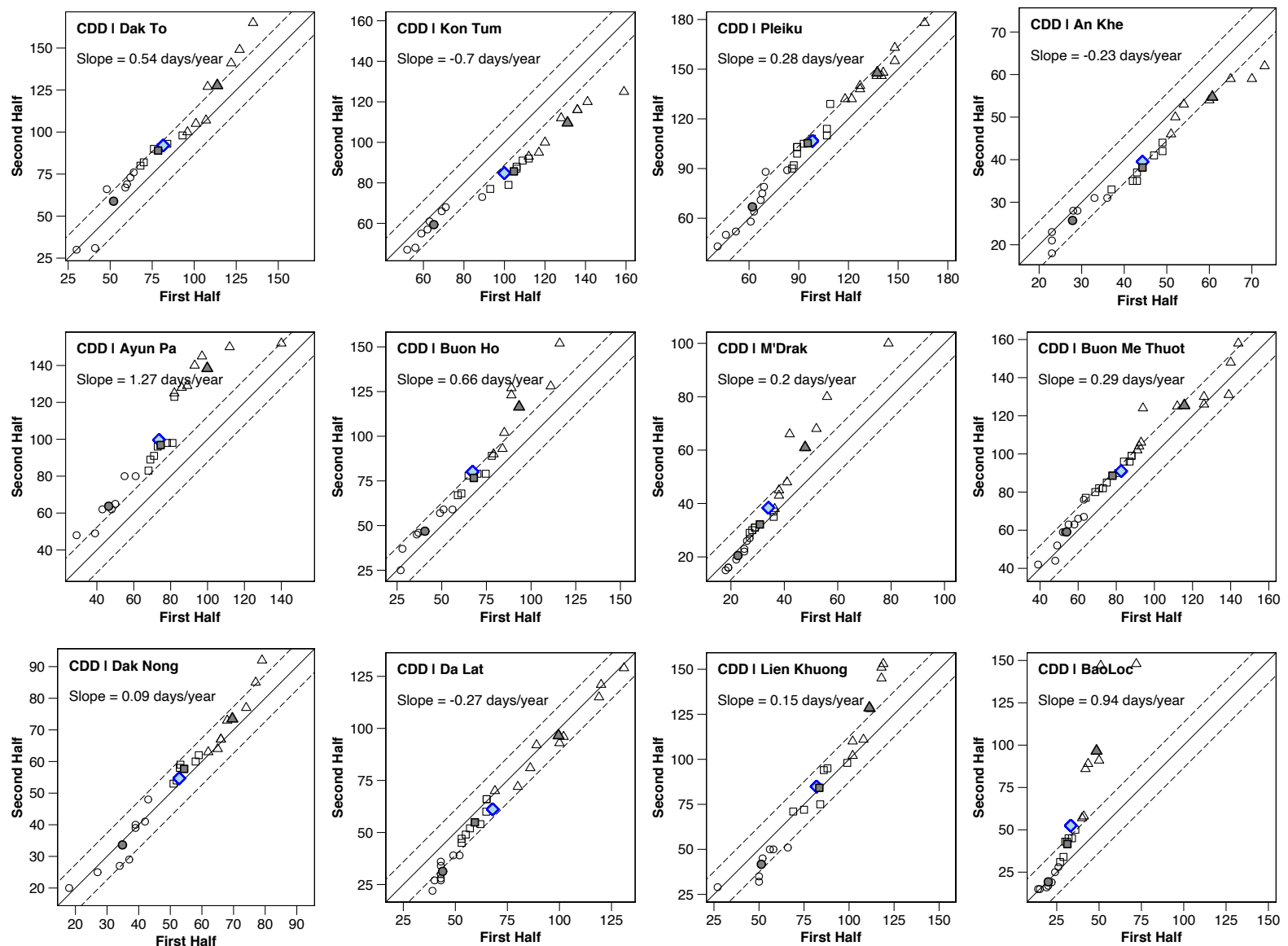

278 Fig. 11 As in Figure 3, but for CDD
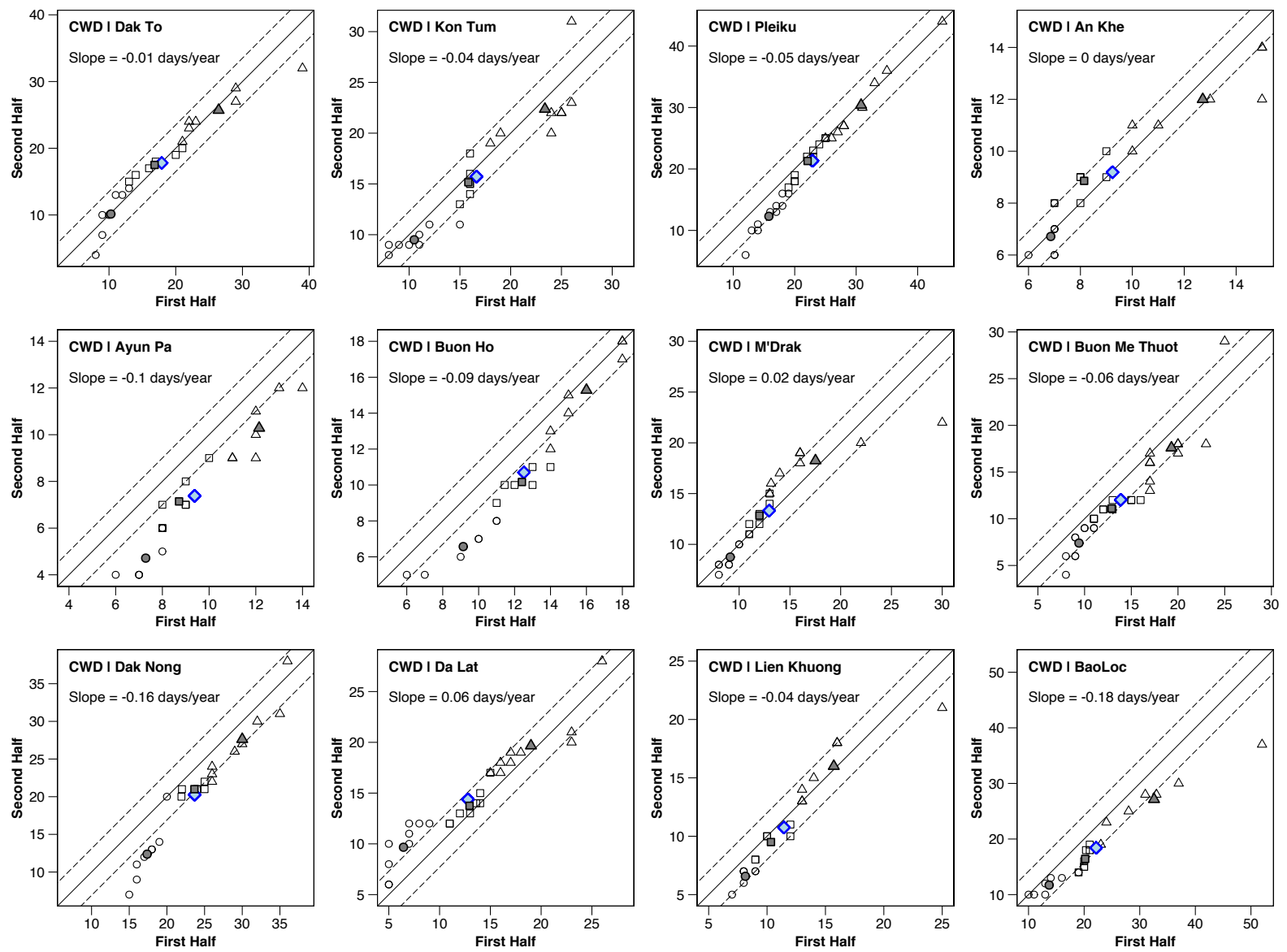

280 Fig. 12 As in Figure 3, but for CWD 
Fig. 11 and Fig. 12 describe possible trend components in the consecutive dry days (CDD) and the consecutive wet days (CWD), respectively. In particular, significant upward trends in CDD were obtained in three stations (i.e., Ayun $\mathrm{Pa}$, Buon Ho, and Bao Loc) with the estimated ITA trend slopes being around 0.66-1.27 days/year, while two stations (i.e., Kon Tum and An Khe) experienced significant declining trends at the rate of approximately from -0.23 to -0.7 days/year. Meanwhile, the overall trends in CWD were characterized by significant declines at four stations (i.e., Ayun $\mathrm{Pa}$, Buon Ho, Dak Nong, and Bao Loc) at the rate of approximately from -0.09 to -0.18 days/year.

Concerning partial trend interpretations of CDD and CWD, Fig. 11 and Fig. 12 further show that the low- and medium-value clusters were dominated mainly by trend-free behaviors. Meanwhile, six stations (i.e., Dak To, Ayun Pa, Buon Ho, M'Drak, Lien Khuong, and Bao Loc) exposed significant increasing trends in the high-value subgroups of CDD. Two stations (i.e., Ayun $\mathrm{Pa}$ and Bao Loc) also exhibited significant decreasing trends in the high-value subgroups of CWD. It is worth noting that the Ayun Pa station was the only one responsible for significant increasing trends in CDD, and significant decreasing trends in CWD within all low-, medium-, and high-value subgroups. On the whole, these findings indicate that dry conditions in the study area have become more frequent and lasted longer during the analyzed period.

\section{Discussion}

Taking all aspects into consideration, it is evident to conclude that the frequency and intensity of extreme rainfall events in the Central Highlands of Vietnam have increased substantially, which is reflected by the domination of significant increases in high-value subgroups of most analyzed indices (such as Rx5day, SDII, R95p, R99p, R50mm, and CDD). These findings are highly consistent with previous in-depth studies over Southeast Asia and the Indo-Pacific region (Caesar et al. 2011; Endo et al. 2009). In particular, Endo et al. (2009) documented that heavy precipitation increased (decreased) over the southern (northern) parts of Vietnam during the period 1950s to 2020s. Endo et al. (2009) also revealed significant increases in SDII, R50mm, and CDD over the Central Highlands of Vietnam, which is highly analogous to the above-mentioned findings. Caesar et al. (2011) demonstrated an increasing trend in R95p, while there was no significant change in Rx5day over the Indo-Pacific region from 1971 to 2005. Caesar et al. (2011) also pointed out several increases (decreases) in Rx5day over the southern (northern) parts of Vietnam, which is partly consistent with those in the Central Highlands as described above. Furthermore, it is expected that the extreme rainfall events in the Central Highlands of Vietnam are likely to become more frequent and intense in the future. Tangang et al. (2018) performed multi-model simulations and projections of four extreme precipitation indices over Southeast Asia under global warming of $2^{\circ} \mathrm{C}$ and indicated significant increases in R50mm and Rx1day in the Central Highlands of Vietnam.

Phuong et al. (2021) pointed out a potential reduction in the total amount of annual rainfall and an increase in the highest intensity of meteorological drought in the Central Highlands by analyzing the lowest values of the 3-month and 12-month Standardized Precipitation Index in each year for the considered period. The present study further substantiated that half of the analyzed stations exhibited significant increases in the high-value subgroups of CDD. These outcomes indicate that the Central Highlands of Vietnam experienced a longer duration of dry conditions during recent decades, especially in the dry season, which could lead to a wide range of constraints on agricultural and other socio-economic activities in the study area.

This study evaluated moderate extremes by analyzing the well-defined ETCCDI extreme precipitation indices. Further investigations should delve deeper into the intensity and frequency of rare extreme events, which might occur once in 20,50, or 100 years. To do this, one can employ extreme-value theory such as the "peaks-over-threshold" or "block maximum" method as recommended by World Meteorological Organization (2009). These approaches are usually applied to the absolute extremes (i.e., Rx1day and Rx5day). Li et al. (2021) highlighted the prime importance of understanding changes in the frequency and intensity of rare extremes because such events often cause more adverse impacts on the society and biophysical systems, and most infrastructure design requires estimation of rare extreme events as well. Moreover, human-induced global warming is bound to cause stronger influences on rare extreme events than moderate ones.

Apart from analyzing individual indices, it is advisable to examine changes in the ratio of a given pair of indices (e.g., the percentage of annual precipitation due to very or extremely wet days). Such an analysis yields more understanding of relatively larger or smaller changes in extreme precipitation events than the total amount (World Meteorological Organization 2009). Another important theme is to explore potential links between large-scale drivers and the variability of precipitation extremes at the regional and local scales. Caesar et al. (2011) pointed out the possibility of a positive correlation between several extreme precipitation indices with a La Niña-like sea surface temperature pattern 
over the Indo-Pacific region. Ho et al. (2011) also pertained to potential changes in heavy rainfall over Vietnam in relationship with the sea surface temperature patterns over the South China Sea. Further studies should pay more attention to large-scale controls on non-monotonic trend components in extreme precipitation indices.

\section{Conclusions}

It is always a good practice to perform a comprehensive evaluation of systematic changes in weather and climate extremes, which is conducive to local decision-makers to put forward more informed decisions on climate change adaptation and mitigation strategies. Thus, the present work aimed to assess and estimate observed changes in heavy rainfall events over the Central Highlands of Vietnam during recent decades. On this basis, ten ETCCDI extreme rainfall indices (i.e., Rx1day, Rx5day, SDII, R95p, R99p, R10mm, R20mm, R50mm, CDD, and CWD) were subjected to temporal trend analysis by employing an innovative trend analysis methodology. The ITA method can identify nonmonotonic trend components in a given hydro-meteorological time series without considering any restrictive assumptions. Such an easy-to-apply but productive technique can be utilized to explore trend possibilities in a wide range of science and engineering fields.

As expected, observed trends in extreme rainfall indices are less spatially consistent across the Central Highlands irrespective of overall or partial trends. Moreover, most analyzed extreme indices exhibited non-monotonic forms, in which low-, medium-, and high-value subgroups exposed opposite trend directions or the same tendency with very different magnitude. In particular, the high-value clusters were characterized mainly by significant increases in most analyzed extreme indices such as Rx5day, SDII, R95p, R99p, R50mm, and CDD. It is worth pointing out that several stations also exposed significant increasing trends within all low-, medium-, and high-value subgroups of Rx5day, R95p, R99p, R20mm, and R50mm (i.e., Kon Tum), SDII (i.e., Bao Loc), and CDD (i.e., Ayun Pa). On the whole, these findings imply significant increases in the frequency and intensity of heavy rainfall events over the Central Highlands of Vietnam during recent decades, which should be taken into account when devising any local adaptation actions to climate-related risks in the study area.

\section{Declarations}

Funding: No funding was received for conducting this study.

Conflicts of interest: The authors have no conflicts of interest to declare that are relevant to the content of this article.

Availability of data and material: Not applicable.

Code availability: Not applicable.

Authors' contributions: Conceptualization: Dang Nguyen Dong Phuong, Nguyen Thi Huyen, Nguyen Kim Loi; Methodology: Dang Nguyen Dong Phuong, Nguyen Thi Huyen, Nguyen Duy Liem; Formal analysis and investigation: Dang Nguyen Dong Phuong, Nguyen Duy Liem, Dang Kien Cuong; Writing - original draft preparation: Dang Nguyen Dong Phuong, Nguyen Thi Hong; Writing - review and editing: Dang Nguyen Dong Phuong, Nguyen Thi Hong, Nguyen Kim Loi; Resources: Dang Kien Cuong, Nguyen Kim Loi; Supervision: Nguyen Kim Loi.

Ethics approval: Not applicable; the study did not include human or animal subject data.

Consent to participate: Not applicable; the study did not include human or animal subject data.

Consent for publication: Not applicable; the study did not include human or animal subject data.

Acknowledgments: The authors thank the editor and reviewers for their constructive comments as well as supportive suggestions. The authors would like to express our heartfelt thanks to the Joint CCl/CLIVAR/JCOMM Expert Team on Climate Change Detection and Indices for developing an internationally coordinated core set of 27 climate extremes indices. The authors are also grateful to Prof. Zekâi Şen for his contributions to the field of hydro-meteorological time series analysis.

\section{References}

Alexander LV, Bador M, Roca R, Contractor S, Donat MG, Nguyen PL (2020) Intercomparison of annual precipitation indices and extremes over global land areas from in situ, space-based and reanalysis products. Environ Res Lett 15:055002. https://doi.org/10.1088/1748-9326/ab79e2 
Almazroui M, Şen Z (2020) Trend Analyses Methodologies in Hydro-meteorological Records. Earth Syst Environ 4:713738. https://doi.org/10.1007/s41748-020-00190-6

Caesar J, Alexander LV, Trewin B, Tse-ring K, Sorany L, Vuniyayawa V, Keosavang N, Shimana A, Htay MM, Karmacharya J, Jayasinghearachchi DA, Sakkamart J, Soares E, Hung LT, Thuong LT, Hue CT, Dung NTT, Hung PV, Cuong HD, Cuong NM, Sirabaha S (2011) Changes in temperature and precipitation extremes over the IndoPacific region from 1971 to 2005. Int J Climatol 31:791-801. https://doi.org/10.1002/joc.2118

Caloiero $\mathrm{T}$ (2018) SPI trend analysis of New Zealand applying the ITA technique. Geosciences 8:101. https://doi.org/10.3390/geosciences8030101

Costa RL, Macedo de Mello Baptista G, Gomes HB, Daniel dos Santos Silva F, Lins da Rocha Júnior R, de Araújo Salvador M, Herdies DL (2020) Analysis of climate extremes indices over northeast Brazil from 1961 to 2014. Weather Clim Extremes 28:100254. https://doi.org/10.1016/j.wace.2020.100254

Dabanlı İ, Şen Z, Yeleğen MÖ, Şişman E, Selek B, Güçlü YS (2016) Trend assessment by the Innovative-Şen method. Water Resour Manage 30:5193-5203. https://doi.org/10.1007/s11269-016-1478-4

Danandeh Mehr A, Vaheddoost B (2020) Identification of the trends associated with the SPI and SPEI indices across Ankara, Turkey. Theor Appl Climatol 139:1531-1542. https://doi.org/10.1007/s00704-019-03071-9

David Bronaugh for the Pacific Climate Impacts Consortium (2020) climdex.pcic: PCIC Implementation of Climdex Routines. R package version 11-11. https:/CRAN.R-project.org/package=climdex.pcic

Dimri AP (2019) Comparison of regional and seasonal changes and trends in daily surface temperature extremes over India and its subregions. Theor Appl Climatol 136:265-286. https://doi.org/10.1007/s00704-018-2486-5

Donat MG, Alexander LV, Yang H, Durre I, Vose R, Caesar J (2013) Global land-based datasets for monitoring climatic extremes. Bull Am Meteorol Soc 94:997-1006. https://doi.org/10.1175/BAMS-D-12-00109.1

Dookie N, Chadee XT, Clarke RM (2019) Trends in extreme temperature and precipitation indices for the Caribbean small islands: Trinidad and Tobago. Theor Appl Climatol 136:31-44. https://doi.org/10.1007/s00704-018-2463-Z

Dunn RJH, Alexander LV, Donat MG, Zhang X, Bador M, Herold N, Lippmann T, Allan R, Aguilar E, Barry AA, Brunet M, Caesar J, Chagnaud G, Cheng V, Cinco T, Durre I, de Guzman R, Htay TM, Wan Ibadullah WM, Bin Ibrahim MKI, Khoshkam M, Kruger A, Kubota H, Leng TW, Lim G, Li-Sha L, Marengo J, Mbatha S, McGree S, Menne M, de los Milagros Skansi M, Ngwenya S, Nkrumah F, Oonariya C, Pabon-Caicedo JD, Panthou G, Pham C, Rahimzadeh F, Ramos A, Salgado E, Salinger J, Sané Y, Sopaheluwakan A, Srivastava A, Sun Y, Timbal B, Trachow N, Trewin B, van der Schrier G, Vazquez-Aguirre J, Vasquez R, Villarroel C, Vincent L, Vischel T, Vose R, Bin Hj Yussof MNA (2020) Development of an Updated Global Land In Situ-Based Data Set of Temperature and Precipitation Extremes: HadEX3. J Geophys Res: Atmos 125:e2019JD032263. https://doi.org/10.1029/2019JD032263

Elouissi A, Şen Z, Habi M (2016) Algerian rainfall Innovative trend analysis and its implications to Macta watershed. Arab J Geosci 9:303. https://doi.org/10.1007/s12517-016-2325-X

Endo N, Matsumoto J, Lwin T (2009) Trends in precipitation extremes over Southeast Asia. Sola 5:168-171. https://doi.org/10.2151/sola.2009-043

García-Cueto OR, Santillán-Soto N, López-Velázquez E, Reyes-López J, Cruz-Sotelo S, Ojeda-Benítez S (2019) Trends of climate change indices in some Mexican cities from 1980 to 2010. Theor Appl Climatol 137:775-790. https://doi.org/10.1007/s00704-018-2620-4

Ho TMH, Phan VT, Le NQ, Nguyen QT (2011) Extreme climatic events over Vietnam from -observational data and RegCM3 projections. Clim Res 49:87-100. https://doi.org/10.3354/cr01021

Ihaka R, Gentleman R (1996) R: a language for data analysis and graphics. J Comput Graph Stat 5:299-314. http://dx.doi.org/10.1080/10618600.1996.10474713

IPCC (2018) Global Warming of $1.5^{\circ} \mathrm{C}$. An IPCC Special Report on the impacts of global warming of $1.5^{\circ} \mathrm{C}$ above preindustrial levels and related global greenhouse gas emission pathways, in the context of strengthening the global response to the threat of climate change, sustainable development, and efforts to eradicate poverty. [MassonDelmotte, V., P. Zhai, H.-O. Pörtner, D. Roberts, J. Skea, P.R. Shukla, A. Pirani, W. Moufouma-Okia, C. Péan, R. Pidcock, S. Connors, J.B.R. Matthews, Y. Chen, X. Zhou, M.I. Gomis, E. Lonnoy, T. Maycock, M. Tignor, and T. Waterfield (eds.)]. In Press. 
Khoi DN, Trong Quan N, Thi Thao Nhi P, Nguyen VT (2021) Impact of Climate Change on Precipitation Extremes over Ho Chi Minh City, Vietnam. Water 13:120. https://doi.org/10.3390/w13020120

Kim Y-H, Min S-K, Zhang X, Sillmann J, Sandstad M (2020) Evaluation of the CMIP6 multi-model ensemble for climate extreme indices. Weather Clim Extremes 29:100269. https://doi.org/10.1016/j.wace.2020.100269

Li C, Zwiers F, Zhang X, Li G, Sun Y, Wehner M (2021) Changes in annual extremes of daily temperature and precipitation in CMIP6 models. J Clim 34:3441-3460. https://doi.org/10.1175/JCLI-D-19-1013.1

Malik A, Kumar A, Pham QB, Zhu S, Linh NTT, Tri DQ (2020) Identification of EDI trend using Mann-Kendall and Şen-Innovative Trend methods (Uttarakhand, India). Arab J Geosci 13:951. https://doi.org/10.1007/s12517-02005926-2

McCuen RH (2018) Critical Values for Şen's Trend Analysis. J Hydrol Eng 23:06018005. https://doi.org/10.1061/(ASCE)HE.1943-5584.0001708

Min S-K, Zhang X, Zwiers FW, Hegerl GC (2011) Human contribution to more-intense precipitation extremes. Nature 470:378-381. https://doi.org/10.1038/nature09763

Murara P, Acquaotta F, Garzena D, Fratianni S (2019) Daily precipitation extremes and their variations in the Itajaí River Basin, Brazil. Meteorol Atmos Phys 131:1145-1156. https://doi.org/10.1007/s00703-018-0627-0

Ngo-Duc T, Kieu C, Thatcher M, Nguyen-Le D, Phan-Van T (2014) Climate projections for Vietnam based on regional climate models. Clim Res 60:199-213. https://doi.org/10.3354/cr01234

Öztopal A, Şen Z (2017) Innovative Trend Methodology Applications to Precipitation Records in Turkey. Water Resour Manage 31:727-737. https://doi.org/10.1007/s11269-016-1343-5

Peel MC, Finlayson BL, McMahon TA (2007) Updated world map of the Köppen-Geiger climate classification. Hydrol Earth Syst Sci 4:439-473. https://doi.org/10.5194/hess-11-1633-2007

Phuong DND, Hai LM, Dung HM, Loi NK (2021) Temporal Trend Possibilities of Annual Rainfall and Standardized Precipitation Index in the Central Highlands, Vietnam. Earth Syst Environ. https://doi.org/10.1007/s41748-021$00211-\mathrm{y}$

Qian C, Zhang X, Li Z (2019) Linear trends in temperature extremes in China, with an emphasis on non-Gaussian and serially dependent characteristics. Clim Dyn 53:533-550. https://doi.org/10.1007/s00382-018-4600-X

Quan NT, Khoi DN, Hoan NX, Phung NK, Dang TD (2021) Spatiotemporal Trend Analysis of Precipitation Extremes in Ho Chi Minh City, Vietnam During 1980-2017. Int J Disaster Risk Sci 12:131-146. https://doi.org/10.1007/s13753-020-00311-9

R Core Team (2021) R: A language and environment for statistical computing. R Foundation for Statistical Computing, Vienna, Austria. URL: https://www.R-project.org/.

Şen Z (2012) Innovative trend analysis methodology. J Hydrol Eng 17:1042-1046. https://doi.org/10.1061/(ASCE)HE.1943-5584.0000556

Şen Z (2014) Trend identification simulation and application. J Hydrol Eng 19:635-642. https://doi.org/10.1061/(ASCE)HE.1943-5584.0000811

Şen Z (2017) Innovative trend significance test and applications. Theor Appl Climatol 127:939-947. https://doi.org/10.1007/s00704-015-1681-X

Sun Q, Zhang X, Zwiers F, Westra S, Alexander LV (2021) A global, continental, and regional analysis of changes in extreme precipitation. J Clim 34:243-258. https://doi.org/10.1175/JCLI-D-19-0892.1

Tangang F, Supari S, Chung JX, Cruz F, Salimun E, Ngai ST, Juneng L, Santisirisomboon J, Santisirisomboon J, NgoDuc T, Phan-Van T, Narisma G, Singhruck P, Gunawan D, Aldrian E, Sopaheluwakan A, Nikulin G, Yang H, Remedio ARC, Sein D, Hein-Griggs D (2018) Future changes in annual precipitation extremes over Southeast Asia under global warming of 2 C. APN Sci Bull 8:3-8. https://doi.org/10.30852/sb.2018.436

Venkata Rao G, Venkata Reddy K, Srinivasan R, Sridhar V, Umamahesh NV, Pratap D (2020) Spatio-temporal analysis of rainfall extremes in the flood-prone Nagavali and Vamsadhara Basins in eastern India. Weather Clim Extremes 29:100265. https://doi.org/10.1016/j.wace.2020.100265 
von Storch H (1995) Misuses of statistical analysis in climate research. In: von Storch H, Navarra A (ed) Analysis of climate variability: applications of statistical techniques. Springer, New York, pp 11-26. https://doi.org/10.1007/978-3-662-03744-7_2

Wickham H, Averick M, Bryan J, Chang W, McGowan LDA, François R, Grolemund G, Hayes A, Henry L, Hester J (2019) Welcome to the Tidyverse. J Open Source Softw 4:1686. https://doi.org/10.21105/joss.01686

World Meteorological Organization (2009) Guidelines on Analysis of extremes in a changing climate in support of informed decisions for adaptation (Albert M.G. Klein Tank, Francis W. Zwiers and Xuebin Zhang). (WMO-TD No. 1500). Geneva.

World Meteorological Organization (2017) WMO Guidelines on the Calculation of Climate Normals (WMO-No. 1203). Geneva.

Yilmaz B (2019) Analysis of hydrological drought trends in the Gap Region (Southeastern Turkey) by Mann-Kendall test and Innovative Sen Method. Appl Ecol Environ Res 17:3325-3342. http://dx.doi.org/10.15666/aeer/1702 33253342

Zhang X, Alexander L, Hegerl GC, Jones P, Tank AK, Peterson TC, Trewin B, Zwiers FW (2011) Indices for monitoring changes in extremes based on daily temperature and precipitation data. WIREs Clim Change 2:851-870. https://doi.org/10.1002/wcc. 147

Zhang X, Zwiers FW (2013) Statistical Indices for the Diagnosing and Detecting Changes in Extremes. In: AghaKouchak A, Easterling D, Hsu K, Schubert S, Sorooshian S (ed) Extremes in a Changing Climate: Detection, Analysis and Uncertainty. Springer Netherlands, Dordrecht, pp 1-14. https://doi.org/10.1007/978-94-007-4479-0 1 